\title{
BMJ Open Values and preferences of men for undergoing prostate-specific antigen screening for prostate cancer: a systematic review
}

\author{
Robin W M Vernooij, ${ }^{1}$ Lyubov Lytvyn, ${ }^{2}$ Hector Pardo-Hernandez, ${ }^{3}$ Loai Albarqouni, ${ }^{4}$ \\ Carlos Canelo-Aybar, ${ }^{3,5}$ Karen Campbell, ${ }^{6}$ Thomas Agoritsas ${ }^{2,7}$
}

To cite: Vernooij RWM, Lytvyn L, Pardo-Hernandez H, et al. Values and preferences of men for undergoing prostate-specific antigen screening for prostate cancer: a systematic review. BMJ Open 2018;8:e025470. doi:10.1136/ bmjopen-2018-025470

- Prepublication history and additional material for this paper are available online. To view these files, please visit the journal online (http://dx.doi. org/10.1136/bmjopen-2018025470).

Received 16 July 2018 Revised 2 August 2018 Accepted 14 August 2018
Check for updates

(C) Author(s) (or their employer(s)) 2018. Re-use permitted under CC BY-NC. No commercial re-use. See rights and permissions. Published by BMJ.

For numbered affiliations see end of article.

Correspondence to Dr Robin W M Vernooij; robinvernooij@gmail.com

\section{ABSTRACT}

Objectives To investigate men's values and preferences regarding prostate-specific antigen (PSA)-based screening for prostate cancer.

Design Systematic review.

Data sources We searched MEDLINE, EMBASE, PsycINF0 and grey literature up to 2 September 2017.

Eligibility criteria Primary studies of men's values and preferences regarding the benefits and harms of PSA screening.

Data extraction and synthesis Two independent reviewers extracted data and assessed risk of bias with a modified version of a risk of bias tool for values and preferences studies, the International Patient Decision Aid Standards instrument V.3 and the Cochrane Collaboration risk of bias tool.

Results We identified 4172 unique citations, of which 11 studies proved eligible. Five studies investigated PSA screening using a direct choice study design, whereas six used decisions aids displaying patientimportant outcomes. The direct choice studies used different methodologies and varied considerably in the reporting of outcomes. Two studies suggested that men were willing to forego screening with a small benefit in prostate cancer mortality if it would decrease the likelihood of unnecessary treatment or biopsies. In contrast, one study reported that men were willing to accept a substantial overdiagnosis to reduce their risk of prostate cancer mortality. Among the six studies involving decision aids, willingness to undergo screening varied substantially from $37 \%$ when displaying a hypothetical reduction in mortality of 10 per 1000 men, to $44 \%$ when displaying a reduction in mortality of 7 per 1000 . We found no studies that specifically investigated whether values and preferences differed among men with family history, of African descent or with lower socioeconomic levels.

Conclusion The variability of men's values and preferences reflect that the decision to screen is highly preference sensitive. Our review highlights the need for shared decision making in men considering prostate cancer screening.

Trial registration number CRD42018095585.

\section{Strengths and limitations of this study}

- We systematically searched for and assessed the quantitative values and preferences related to benefits and harms of prostate-specific antigen (PSA) screening among men considering screening, to inform a linked BMJ Rapid Recommendations guideline.

- We used rigorous systematic review methodology, and a guideline panel of frontline clinicians, methodologists and patient partners identified patient-important outcomes related to PSA screening.

- We did not identify studies that explicitly asked men about the thresholds of benefits and harms related to PSA screening that would be important to them.

- Most studies included several characteristics of screening options (eg, costs and time intervals), which might influence the willingness to undergo screening more than potential benefits and harms.

- A meta-analysis was not possible, thus we reported a narrative summary of the included studies.

\section{INTRODUCTION}

Population prostate-specific antigen (PSA)based screening for prostate cancer remains controversial. Although PSA screening leads to increased incidence of prostate cancer, it results at best in a small absolute reduction in disease-specific mortality ( 1 fewer deaths per 1000 men over 10 years). ${ }^{1}$ It is unclear whether the overall benefits of screening outweigh the potential harms and burden resulting from the cascade of diagnostic imaging and biopsies (eg, bleeding, pain, infections and hospital readmissions), as well as complications from subsequent prostate cancer treatment (eg, urinary incontinence, erectile dysfunction or bowel-related complaints). ${ }^{1}$ This uncertainty is reflected by a lack of consensus across international guidelines, ${ }^{2-7}$ as well as the important variability of the screening practices worldwide. ${ }^{8-14}$ 
Box 1 Linked articles in this BMJ Rapid Recommendation cluster

- Tikkinen KA0, Dahm P, Lytvyn L, et al . Prostate cancer screening with prostate-specific antigen (PSA) test: a clinical practice guideline. BMJ 2018:362:k3581. doi:10.1136/bmj.k3581. ${ }^{2}$

- Summary of the results from the Rapid Recommendation process

- Ilic D, Djulbegovic M, Jung JH, et al . Prostate cancer screening with prostate-specific antigen (PSA) test: a systematic review and meta-analysis. BMJ 2018:362:k3519. doi:10.1136/bmj.k3519.

- Systematic review and meta-analysis of all available randomised trials that assessed PSA based screening for prostate cancer.

- Vernooij RWM, Lytvyn L, Pardo-Hernandez H, et al. Values and preferences of men for undergoing prostate-specific antigen screening for prostate cancer: a systematic review. BMJ Open 2018.

- MAGICapp (https://app.magicapp.org/public/guideline/n32gkL).

- Expanded version of the results with multilayered recommendations, evidence summaries, and decision aids for use on all devices.

Because prostate cancer will often-although not alwaysremain indolent, and result in substantial overdiagnosis and overtreatment, the decision to undergo PSA screening is highly preference-sensitive. Men who place a high value in avoiding complications from biopsies and subsequent treatment may be more likely to decline screening, whereas men who place a higher value in even a small reduction of prostate cancer, as well as those who are more concerned to rule out the diagnosis, are likely to choose screening. ${ }^{2}$ Decision aids may facilitate understanding of the benefits and harms of alternative choices in decision making, and help men to make a decision in line with their own values and preferences. ${ }^{15} 16$

A large cluster randomised trial of PSA testing conducted among 419582 British men in general practices triggered a BMJ Rapid Recommendation (RapidRec) guideline ${ }^{2} 17$ - a series of trustworthy recommendations published in response to potentially practice-changing evidence. ${ }^{18} \mathrm{An}$ international panel appraised the whole body of evidence in an updated systematic review of the benefits and harms of PSA screening for prostate cancer, ${ }^{1}$ and issued a recommendation $^{2}$ (box 1). Men's preferences about undergoing screening, when presented with information about the potential benefits and harms, remains unclear. To inform the RapidRec guideline work, we conducted this systematic review to examine men's values and preferences regarding prostate cancer screening.

\section{METHODS}

The study protocol was registered in the International ProspectiveRegisterofSystematicreviews:CRD42018095585. We followed the Meta-analysis of Observational Studies in Epidemiology (MOOSE) reporting guidelines for this article (see online supplementary appendix I).

\section{Eligibility criteria}

We included studies that reported men's stated preference to screen or not to screen, based on their values and preferences concerning PSA screening patient-important benefits and harms, as defined by the BMJ RapidRecs guideline panel. ${ }^{2}$ Additionally, we examined the stated intention to undergo screening based on information regarding the patient-important outcomes presented in decision aids. We excluded: (1) analyses of data that were not reported by patients (eg, databases of health records) or on outcomes outside the perspective of men considering prostate cancer screening; (2) studies reporting only outcome prioritisation, time trade off, health state values or willingness to pay; (3) studies reporting only access to screening; (4) studies on knowledge or awareness about screening; (5) cost-effectiveness studies; (6) qualitative studies; (7) case report and case series and (8) studies published in a language other than English.

\section{Search strategy}

We searched MEDLINE, EMBASE and PsycINFO from 1980 to 2 September 2017, using a combination of keywords and MeSH/EMTREE terms related to prostate cancer and cancer screening, and applied a search filter for patient's values and preferences ${ }^{19}$ (see online supplementary appendix II). Additionally, we searched the conference abstracts from the annual meetings of the European Association of Urology and American Urological Association from 2007 to 2017. We also searched through Google for 'prostate cancer screening' and 'values and preferences', reviewing the first five pages of results. References of the included studies were screened to identify other potentially eligible studies.

\section{Study selection and quality assessment}

We screened titles and abstracts, as well as full-text screening, independently and in duplicate by paired reviewers (RV, LL, HP, CC, LA, KC). Disagreements were resolved by consensus or consultation with a a third reviewer (TA). The risk of bias was assessed independently and in duplicate. For studies that reported men's stated preferences about prostate cancer screening (eg, discrete choice experiments), we used a risk of bias tool developed specifically for values and preferences studies. ${ }^{20}$ For studies that investigated the effect of decision aids on men's intentions to undergo screening, we used two instruments, similar to a recent study of decision aids for prostate cancer screening. ${ }^{21}$ First, we assessed the risk of bias using a modified version of the Cochrane Collaboration risk of bias tool addressing randomisation sequence generation, concealment, blinding of data collectors, blinding of data analysts and missing data-separately for each outcome. For each criterion, studies were judged to be at either high, unclear or low risk of bias. Additionally, we evaluated the decision aids using a modified version of the International Patient Decision Aid Standards instrument V.3 for screening. ${ }^{22}$ We rated each criterion as met or not met. The full risk of bias assessments can be found in the online supplementary appendix III. 


\section{Data collection and presentation}

Two reviewers extracted the data from the included studies, independently and in duplicate, using a standardised form, including: first author, publication year, study design (eg, discrete choice experiment, decision aids study), setting, number of participants, participant's demographics (eg, age, previous screening, prostate cancer family history). For decision-aids studies, we reported the intention to screen after exposure to the decision aids. Due to the heterogeneity of the data, we summarised the study results in a narrative format.

\section{BMJ Rapid Recommendations and patient involvement}

A panel of clinicians, including urologists, family doctors, methodologists and men considering screening, were responsible for creating rapid and trustworthy recommendations. ${ }^{12}$ Three men eligible for PSA screening were members of the guideline panel that informed the protocol for this review, and received personal training and support to optimise contributions throughout the guideline development process. These panel members identified and prioritised patient-important outcomes, and led the discussion on values and preferences. The guideline panel defined the population and all patient-important outcomes of interest, as well as practical issues related to PSA screening. To provide the guideline panel with the best available evidence, a linked systematic review was conducted that summarised outcomes related to the benefits and harms of PSA screening. ${ }^{1}$ The BMJ RapidRec panel developed recommendations using the Grading of Recommendations, Assessment, Development and Evaluation framework, and considered both the evidence from the systematic review on the effectiveness and safety of PSA screening, and the evidence from this review on men's values and preferences. ${ }^{23}$ Finally, the results of the two reviews and the panel deliberations were used to inform the online consultation decision aids generated from the evidence summary supporting this BMJ RapidRec, ${ }^{2}$ available online through the MAGICapp (www.magicapp.org).

\section{RESULTS}

\section{Study characteristics}

We identified 4172 unique citations, of which 200 proceeded to full-text review (see online supplementary appendix IV for the reasons of exclusion). Eleven

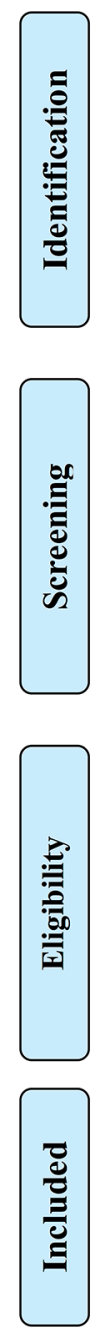

$$
\begin{aligned}
& \text { Records identified through database } \\
& \text { searching } \\
& (\mathrm{n}=6,019)
\end{aligned}
$$

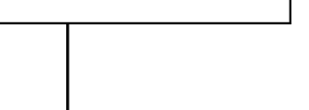

Figure 1 Flow chart of the search strategy and evidence selection of the included studies. 
Table 1 Characteristics of the included studies

\begin{tabular}{|c|c|c|c|c|c|c|c|}
\hline Study & Design & Country & $\begin{array}{l}\text { Years of } \\
\text { data collection }\end{array}$ & $\begin{array}{l}\text { Number of } \\
\text { participants }\end{array}$ & $\begin{array}{l}\text { Age } \\
\text { (mean, } \\
\text { SD) }\end{array}$ & $\begin{array}{l}\text { Previous PSA } \\
\text { screening }\end{array}$ & $\begin{array}{l}\text { Family history } \\
\text { of prostate } \\
\text { cancer }\end{array}$ \\
\hline \multicolumn{8}{|c|}{ Studies reporting direct choice related to PSA screening acceptability } \\
\hline Cantor et $\left.a\right|^{24}$ & DCE & USA & $1997-1998$ & 168 & $56(N R)$ & $\begin{array}{l}\text { Ever }=50 \% \\
\text { Unsure }=14 \%\end{array}$ & $\begin{array}{l}17 \% \text { have } \\
\text { relative with } \\
\text { prostate cancer }\end{array}$ \\
\hline de Bekker-Grob et al ${ }^{25}$ & DCE & $\begin{array}{l}\text { The } \\
\text { Netherlands }\end{array}$ & 2013 & 1000 & $63.3(5.2)$ & NR & $\begin{array}{l}51 \% \text { know } \\
\text { someone with } \\
\text { prostate cancer }\end{array}$ \\
\hline $\begin{array}{l}\text { Howard et } a l^{26} \text { and } \\
\text { Pignone et } a l^{29}\end{array}$ & DCE & $\begin{array}{l}\text { Australia } \\
\text { and USA }\end{array}$ & 2011 & 911 & $59.8(5.6)$ & $\begin{array}{l}\text { Ever }=20.9 \% \\
\text { Within past } \\
\text { year=42\% }\end{array}$ & $0 \%$ \\
\hline Howard et $a l^{27}$ & DCE & USA & NR & 662 & $55(9)$ & $\begin{array}{l}\text { Ever=44.6\% } \\
\text { Within past } \\
\text { year=28.1\% }\end{array}$ & $0 \%$ \\
\hline van den Bruel et a $\left.\right|^{28}$ & DCE & UK & 2014 & 490 & $\begin{array}{l}46.9 \\
\text { (range: } \\
19-87 \text { ) }\end{array}$ & Ever $=53.8 \%$ & NR \\
\hline \multicolumn{8}{|c|}{ Studies of decision aids reporting men's willingness to undergo PSA screening } \\
\hline Gattellari and Ward ${ }^{30}$ & $\mathrm{RCT}$ & Australia & NR & 258 & $54(8.55)$ & NR & NR \\
\hline Petrova et $a l^{31}$ & $\mathrm{RCT}$ & USA & NR & 256 & $36(13)$ & Ever $=18 \%$ & $\begin{array}{l}27 \% \text { had } \\
\text { a friend or } \\
\text { a relative } \\
\text { diagnosed with } \\
\text { prostate cancer }\end{array}$ \\
\hline Sheridan et $\left.a\right|^{32}$ & $\mathrm{RCT}$ & USA & NR & 188 & $60(9)$ & Ever $=70 \%$ & $\begin{array}{l}20 \% \text { had any } \\
\text { family history }\end{array}$ \\
\hline Sheridan et $a /^{33}$ & RCT & USA & NR & 775 & NR & Ever $=80 \%$ & NR \\
\hline Taylor et $\left.a\right|^{34}$ & $\mathrm{RCT}$ & USA & 2007-2011 & 1893 & $56.9(6.8)$ & $\begin{array}{l}\text { Ever }=86.3 \% \\
\text { Within past } \\
\text { year }=59.3 \%\end{array}$ & $\begin{array}{l}23 \% \text { had family } \\
\text { history }\end{array}$ \\
\hline Wilt et $a l^{35}$ & $\mathrm{RCT}$ & USA & 1998 & 342 & $72.8(8.4)$ & $\begin{array}{l}\text { Within past } \\
\text { year }=31 \%\end{array}$ & $14 \%$ \\
\hline
\end{tabular}

DCE, discrete choice experiment; NR, not reported; PSA, prostate-specific antigen; RCT, randomised controlled trial.

studies were ultimately eligible for our review (figure 1). Of the included studies, five investigated men's stated preferences regarding prostate cancer screening, ${ }^{24-28}$ and six investigated men's willingness to undergo screening when presented with a decision aid. ${ }^{29-34}$

The studies were all conducted in high-income countries: Australia (1), The Netherlands (1), the UK (1), the USA (7) and both the USA and Australia (1) (table 1 ). The proportion of men who had previously undergone prostate cancer screening prior to study participation varied from $0 \%$ to $80 \%$ across studies. Similarly, the proportion of men with prostate cancer family history varied from $0 \%$ to $27 \%$. In one study, $51 \%$ of the included men reported to know someone that had prostate cancer without any further definition. ${ }^{25}$ Of the studies that reported their funding source $(82 \%)$, all were sponsored by public grant institutions. About half of the studies (55\%) stated that the authors did not have any relevant conflicts of interest, and the other studies did not report about authors' conflicts of interest.

\section{Study quality}

Most stated preference studies were of moderate to high risk of bias, usually due to limitations in the attrition and data analysis domains (table 2). One study included participants from the general population ${ }^{25}$; however, the other studies mainly referred to outpatients or research panel participants. However, most of the studies did not report enough information to assess the attrition bias, only de Bekker-Grob et al..$^{25}$ reported the survey response rate $(46 \%) .{ }^{25}$ Only one study was considered at low risk of bias in the measurement instrument subdomain. ${ }^{26}$ In this study, the authors adequately used an instrument for electing the relative importance of valid and reliable outcomes, administered the instrument in the intended 


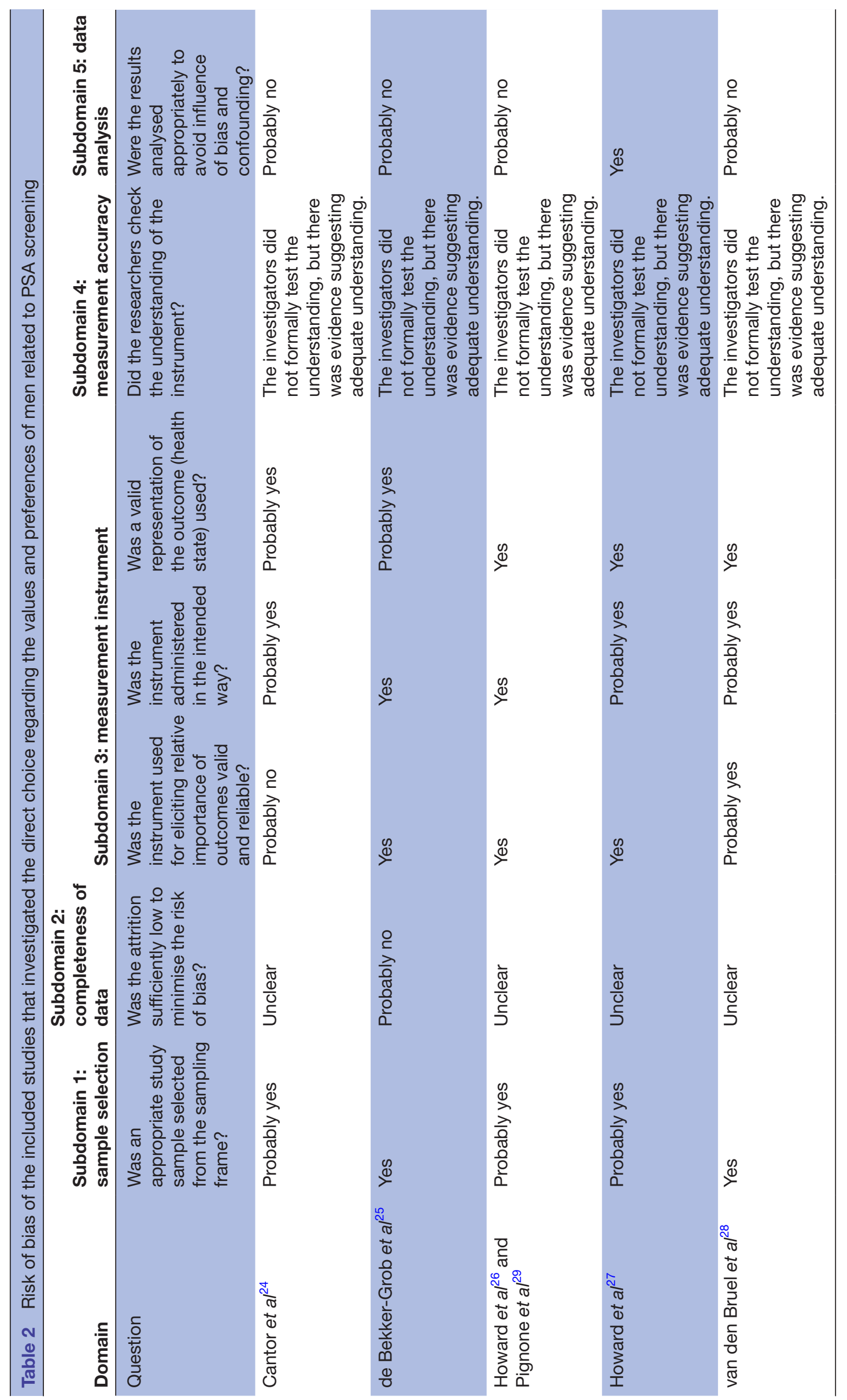


way and used a valid representation of the outcome. None of the studies formally tested the understanding of the used instruments.

The decision-aids studies were mostly of low to moderate risk of bias; however, there were several methodological limitations (see online supplementary appendix V). One study applied adequate random sequence generation and allocation concealment. ${ }^{33}$ Due to the nature of the intervention, most patients were aware of the allocated intervention. Moreover, blinding procedures for the outcome collector or analysts were not reported; however, risk of bias for random allocation or blinding was not considered important for this review since we are interested solely in the results after exposure. Four studies described the amount of missing data. ${ }^{29}{ }^{32-34}$ Furthermore, most studies described the aim of screening, but only two (33\%) decision-aids studies included information about the rates of diagnostic test accuracy. Similarly, less than half of the decision aids in the included studies described the next steps in the patient's pathway after obtaining the screening result (positive or negative).

\section{Stated preferences related to PSA screening}

In total, there were five studies on men's stated preferences related to prostate cancer screening, all of which were discrete choice experiments. ${ }^{24-29}$ One study included a discrete choice experiment, as well as a balance sheet task (unlabelled descriptions of the options). ${ }^{26}{ }^{29}$ Although studies displayed estimates on patient-important benefits (risk reduction of prostate cancer-specific mortality) and harms (eg, increased unnecessary biopsies, unnecessary treatment, risk of incontinence and bowel problems and risk of impotence), the objectives of the studies differed and the outcomes reported were heterogeneous. A meta-analysis was therefore not possible, and we summarised the evidence narratively (table 3 ).

The study by de Bekker-Grob et $a t^{25}$ investigated how much men are willing to forego screening, if it involved a small benefit in prostate cancer mortality, in order to decrease the likelihood of unnecessary biopsies, unnecessary treatments and more frequent screening. ${ }^{25}$ For example, participating men were willing to trade a $2.0 \%$ (95\% CI 1.6 to 2.4 ) and $1.8 \%$ (95\% CI 1.3 to 2.3 ) decrease in mortality risk reduction, for a $10 \%$ decrease in unnecessary treatment risk and unnecessary biopsy risk, respectively.

In the study by Howard et al, participating men were asked how many extra men who would experience unnecessary biopsies or incontinence and bowel problems were acceptable in order to avoid one prostate cancer death. ${ }^{27}$ These results are stratified by age, and were markedly different between the age categories. Men aged 50-59 years were willing to accept 233 in 10000 (95\% CI 224 to 242) extra men with unnecessary biopsies to avoid one prostate cancer death in 10000 men screened, whereas both younger (aged 40-49 years) and older (aged 60-69 years) men accepted fewer unnecessary biopsies. Similarly, men aged 50-59 years were willing to accept 72 in 10000 (95\% CI 69 to 75) extra men with incontinence or bowel problem to avoid one prostate cancer death in 10000 men screened, but this was lower in both younger and older men. ${ }^{27}$

In the study by van den Bruel $e t a l_{,}^{28}$ the authors examined the number of cases of overdetection that the men were willing to accept for a reduction in cancer-specific mortality. ${ }^{28}$ To reduce the prostate cancer mortality by $10 \%$ and $50 \%$, the participating men were willing to accept 126 (95\% CI 100 to 150$)$ and 231 (95\% CI 200 to 250) cases of overdetection in 1000 people screened, respectively. The authors concluded that there was variability in the acceptability of overdetection in cancer screening.

Finally, in the study reported by Pignone et $a l^{29}$ and Howard et $a l,{ }^{26}$ the chances of prostate cancer diagnosis, prostate cancer mortality, biopsies and developing impotence or incontinence as a result of screening were included, and men were asked about their willingness to undergo screening using three different values elicitation techniques. ${ }^{26}$ The proportion of men who wanted to undergo PSA screening compared with no screening ranged from $20 \%$ to $44 \%$.

\section{Studies of decision aids and men's intentions to undergo screening}

In total, we identified six studies in which decision aids displaying screening-related patient-important outcomes (eg, prostate cancer diagnosis, prostate cancer mortality risk, unnecessary biopsy risk) were presented to men, and asking for their willingness to get screened. ${ }^{30-35}$ The decision aids presented information in different ways, which resulted in considerable heterogeneity in how outcomes were reported (table 4).

The study by Gattellari et $a l^{30}$ presented a prostate cancer diagnosis in $10 \%$ of the men aged up to 75 years, whereas Sheridan et $a l^{22}$ presented a prostate cancer diagnosis of $5 \%$ of men aged 50 years and $25 \%$ of men aged 70 years. ${ }^{30}{ }^{32}$ Furthermore, Taylor $e t a l^{84}$ used a prostate cancer diagnosis of $16 \%$ of all men, and Wilt et $a l^{35}$ presented that $10 \%$ of all men get prostate cancer. ${ }^{3435}$ Although variability in the presentation of the outcome prostate cancer mortality was identified, the quantitative effect estimates were comparable, since all studies report a prostate cancer mortality of around $1 \%-3 \%$. Finally, two studies included quantitative information on the effect of unnecessary biopsies and treatment. This includes a proportion of $30 \%$ of the men that experience serious infection due to biopsies, ${ }^{33}$ and a larger variability on the unnecessary treatment information, from $30 \%$ sexual and urinary problems due to treatment to $2 \%$ unnecessary treatments. ${ }^{3133}$

\section{DISCUSSION}

\section{Principal findings}

We have conducted the first systematic review of values and preferences of men from the general population related to their willingness to undergo prostate cancer screening. Overall, there was considerable heterogeneity across men's values and preferences regarding the important benefits and harms related to prostate cancer screening. Several, 
Table 3 Results of the studies reporting direct choice related to PSA screening acceptability

\begin{tabular}{|c|c|}
\hline Study & Outcome/presentation \\
\hline Cantor et $\mathrm{al}^{24}$ & $\begin{array}{l}\text { Preference for PSA screening or no screening, based } \\
\text { on individualised decision-analytic model. }\end{array}$ \\
\hline $\begin{array}{l}\text { de Bekker- } \\
\text { Grob et } a l^{25}\end{array}$ & $\begin{array}{l}\text { Willingness to trade per cent decrease in screening- } \\
\text { related mortality risk reduction (from } 3.5 \% \text { to } \\
3.2 \%, 10 \% \text { RRR; } 2.8 \%, 20 \% \text { RRR; } 2.5 \%, 30 \% \text { RRR; } \\
1.8 \%, 50 \% \text { RRR), per cent decrease in burden from } \\
\text { unnecessary biopsies }(20 \%, 40 \%, 60 \%, 80 \%) \text { and } \\
\text { unnecessary treatments }(0 \%, 20 \%, 50 \%, 80 \%) \text {. }\end{array}$ \\
\hline
\end{tabular}

Howard et $a^{26}$ Preference for a PSA screening option compared with and Pignone et $\left.a\right|^{29}$ a no screening option, based on a discrete choice experiment*, and balance sheet task (unlabelled description of benefits and harms) $\dagger$, over 10 years.

Howard et $\mathrm{al}^{27}$ Preference for the number of men who would experience screening-related harms (unnecessary biopsies, incontinence/bowel problems) to avoid one prostate cancer death in 10000 men screened.

\section{Results}

- $28.6 \%$ of men preferred screening to no screening.

- $34.5 \%$ of couples (men and their wives) preferred screening to no screening.

- $2.0 \%$ decrease in screening-related mortality risk reduction $(95 \% \mathrm{Cl} 1.6$ to 2.4$)$ for $10 \%$ less risk of unnecessary treatment.

- $1.8 \%$ decrease in screening-related mortality risk reduction $(95 \% \mathrm{Cl} 1.3$ to 2.3$)$ for $10 \%$ less risk of unnecessary biopsies.

Balance sheet: $43.7 \%$ prefer the PSA screening option.

- Discrete choice experiment: $20.2 \%$ prefer the PSA screening option.

Men aged 40-49 years:

- 65 in 10000 (95\% Cl 59 to 70) extra men with unnecessary biopsies.

- 31 in 10000 (95\% Cl 28 to 34) extra men with incontinence/bowel problems.

Men aged 50-59 years:

- 233 in 10000 (95\% Cl 224 to 242$)$ extra men with unnecessary biopsies.

- 72 in 10000 (95\% Cl 69 to 75) extra men with incontinence/bowel problems.

Men aged 60-69 years:

- 153 in 10000 (95\% Cl 149 to 158$)$ extra men with unnecessary biopsies.

- 54 in 10000 (95\% Cl 52 to 55) extra men with incontinence/bowel problems.

van den Bruel Willingness to accept overdetection to trade off et $a^{28} \quad$ reduction in prostate cancer-specific mortality.
$10 \%$ prostate cancer-specific reduction in mortality, 126 cases $(95 \% \mathrm{Cl} 100$ to 150$)$ of overdetection per 1000 people screened:

- $5.5 \%(95 \% \mathrm{Cl} 3.7$ to 7.9$)$ accepts no overdetection at all.

- $7.1 \%$ (95\% Cl 5.0 to 9.8) accepts overdetection in the complete population

$50 \%$ prostate cancer-specific reduction in mortality, 231 cases $(95 \% \mathrm{Cl} 200$ to 250$)$ of overdetection per 1000 people screened:

- $4.5 \%$ (95\% Cl 2.8 to 6.7$)$ accepts no overdetection at all.

- $9.2 \%(95 \% \mathrm{Cl} 6.8$ to 12.1$)$ accepts overdetection in the complete population.

${ }^{*}$ Discrete choice experiment, levels of attributes, over 10 years: chance of prostate cancer diagnosis 40 in 1000,60 in 1000 or 80 in 1000 with screening, vs 40 in 1000 with no screening; chance of dying from prostate cancer 2 in 1000,3 in 1000 or 4 in 1000 with screening, vs 4 in 1000 with no screening; chance of having a prostate biopsy as a result of screening 0 in 1000, 240 in 1000 or 330 in 1000 with screening, vs 0 in 1000 with no screening; chance of becoming impotent or incontinent as a result of screening 0 in 1000,10 in 1000 or 20 in 1000 with screening, vs 0 in 1000 with no screening.

†Balance sheet task, features of options, over 10 years: chance of prostate cancer diagnosis for 40 out of 1000 men with no screening, vs 80 out of 1000 men with screening; chance of dying from prostate cancer for 4 out of 1000 men with no screening, vs 3 out of 1000 men with screening; chance of having a prostate biopsy as a result of screening for 0 out of 1000 men with no screening, vs 240 out of 1000 men with screening; chance of becoming impotent or incontinent as a result of screening for 0 out of 1000 men with no screening, vs 20 out of 1000 men with screening.

PSA, prostate-specific antigen; RRR, relative risk reduction.

but not all, studies reported that many men among the general population were willing to accept considerable risk of harm such as unnecessary biopsies, risk of impotence and risk of incontinence, in order to achieve a small reduction in their risk of prostate cancer mortality. It is unclear, however, how much of the variability in preferences was due to the differences in study methodology and reporting. 
Table 4 Results of the studies that examined the effect of a decision aid on the men's motivation for undergoing PSA screening

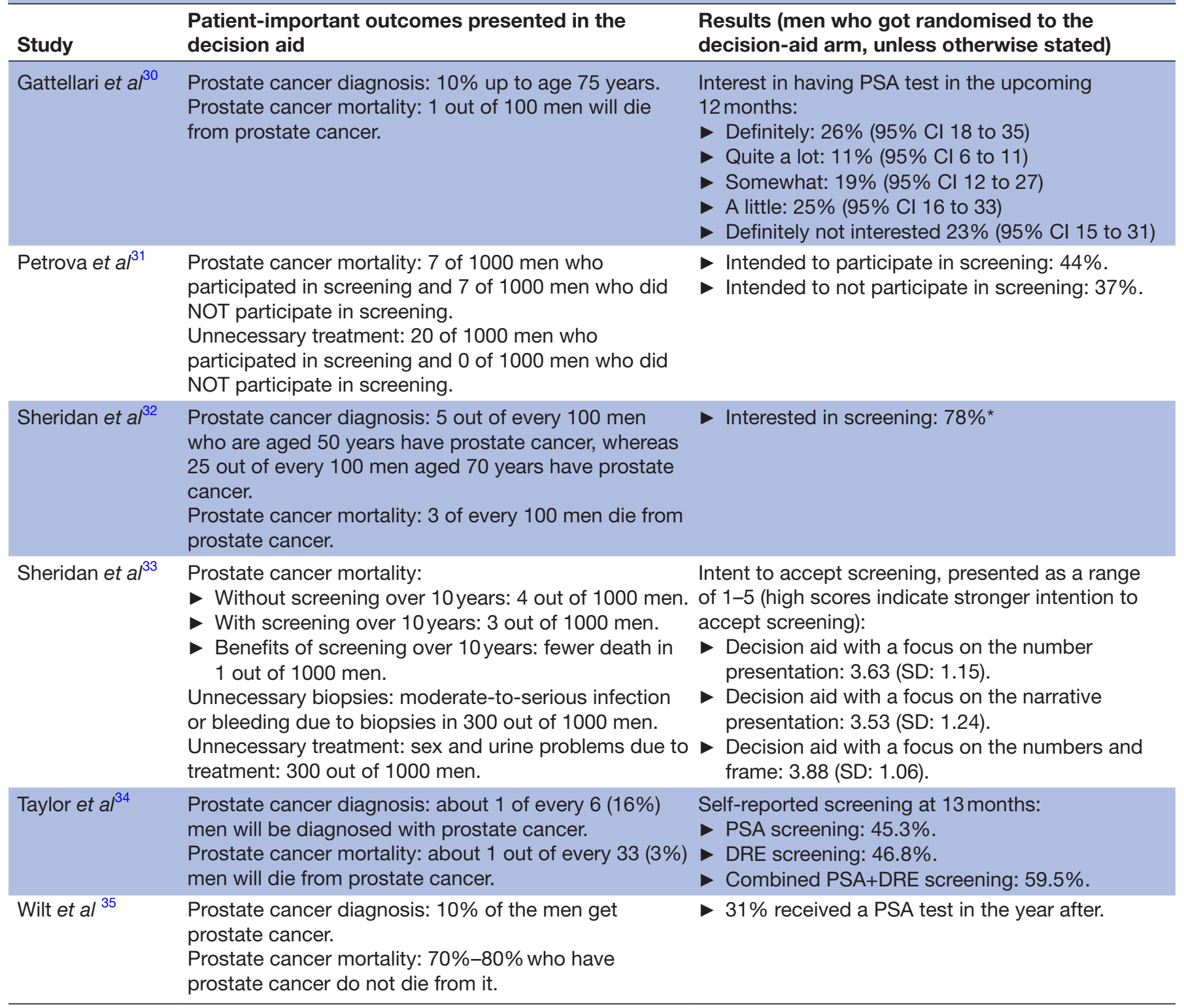

*All study participants (not randomised trial).

DRE, digital rectal examination; PSA, prostate-specific antigen.

\section{Context in relation to previous research}

Patients' values and preferences encompass perspectives, priorities, beliefs, expectations, values and goals for health and life when considering the potential benefits, harms, costs and inconveniences of management options available. ${ }^{36}$ To inform the RapidRecs guideline, ${ }^{2}$ we limited our scope to quantitative data on thresholds related to benefits and harms, which was deemed the most important information for the panel's decision making. There is currently no formal guidance for conducting systematic reviews of patients' values and preferences to inform decision makers. ${ }^{37} 38$ Clinical practice guidelines have used values and preferences studies to inform outcome importance, such as measures of health state utilities as well as non-utilities (eg, questionnaires, qualitative studies). ${ }^{20} 39$
In addition, qualitative research on values and preferences in particular have been used for contextualising guidelines with regard to feasibility and acceptability of interventions, and identifying barriers and facilitators to implementation of recommendations. ${ }^{40}$

A recent qualitative review on men's perspectives of prostate cancer screening identified five themes that influence men's choices about screening: social prompting, gaining decisional confidence, preserving masculinity, avoiding the unknown and uncertainties and prohibitive costs. ${ }^{41}$ The review did not discuss the degree of benefits and harms considered important nor report on heterogeneity across individuals' perceptions; however, the authors highlighted the 'complex decisional matrix' of deciding whether to be screened. Another systematic 
review summarised studies eliciting preferences about screening test attributes and healthcare delivery attributes regarding various cancer screening (prostate, colon, breast). ${ }^{42}$ Efficacy, process and cost were significant determinants of choice, whereas healthcare delivery attributes had mixed effects. The magnitude of effects deemed important, however, was not reported.

\section{Unanswered questions and future research}

The RapidRecs guideline panel identified several subgroups of men who might express different distribution values and preferences regarding prostate cancer screening. These included men with family history, men of African descent, men with a lower socioeconomic status and men that previously had screening or biopsies. ${ }^{12}$ However, none of the studies that met our eligibility criteria investigated whether the men's values and preferences differed across subgroups. Identifying whether there are differences among men in these subgroups regarding their judgements of benefits and harms would be important to assess the need for specific recommendations.

There is considerable variability in the design and reporting of values and preferences studies, which are often not amenable for producing absolute estimates of effect regarding benefits and harms that would be helpful for decision making. More standardised reporting would ensure that decision makers are able to use data from values and preferences research. Additionally, in this systematic review we focused on the values and preferences that can be used to inform the magnitude of effect in terms of patient-important outcomes that men would consider important to undergo screening. Potentially other values and preferences outcomes, including those derived from utilities and qualitative studies, could provide additional insights.

Many factors probably play a role in what shapes individual decisions, and some of these factors could relate to incentives from others: family members, coworkers, media as well as recommendations from healthcare providers. A challenge of the research in this field is to disentangle men's true values and preferences from responses to such incentives. Potential avenues of research may include the mapping of screening rates, and their evolution in parallel to recommendation of screening campaigns across countries. Such research may, however, be limited in its conclusion because of the paucity of reliable data, and the multiple outside factors that may be at play.

\section{Strengths and weaknesses}

Our systematic review has several strengths. First, we followed the MOOSE guidelines and prospectively registered our protocol. Second, we followed rigorous systematic review methodology, including a systematic comprehensive search using a validated filter for the identification of patient's values and preferences, and assessment of study quality.
There are also limitations to our systematic review. First, the results reported are intrinsically limited by the specific design of the included studies, and the information that men were exposed to. For example, most studies included several characteristics of the screening options (eg, cost, intervals of screening), which may have influenced some men's willingness to screen more than the potential benefits and harms. Second, none of the studies explicitly asked participants what thresholds of benefit and harm would be important to them. Due to suboptimal reporting or heterogeneous study design across the included studies, we were not able to meta-analyse any data, and were limited to narratively summarising the included studies. Third, willingness or intention to screen may not reflect individuals' future behaviour, ${ }^{34}$ thus our inferences about acceptability are uncertain.

\section{CONCLUSIONS}

The variability of men's values and preferences, particular to the degree that their information needs are met, reflect that the decision to screen is highly preference sensitive. As a consequence, men considering screening should be assisted through shared decision making to ensure that they are reaching a decision in line with their values.

\section{Author affiliations \\ ${ }^{1}$ Department of Research, Netherlands Comprehensive Cancer Organisation, Utrecht, The Netherlands \\ ${ }^{2}$ Department of Health Research Methods, McMaster University, Hamilton, Burlington, Canada \\ ${ }^{3}$ Iberoamerican Cochrane Centre, Institute of Biomedical Research, Barcelona, Spain ${ }^{4}$ Center for Research in Evidence-Based Practice (CREBP), Bond University Faculty of Health Sciences and Medicine, Gold Coast, Australia \\ ${ }^{5}$ Universidad Peruana de Ciencias Aplicadas, Lima, Peru \\ ${ }^{6}$ School of Nursing, McMaster University, Ontario, Canada \\ ${ }^{7}$ Division General Internal Medicine \& Division of Clinical Epidemiology, University Hospitals of Geneva, Geneva, Switzerland}

Contributors All authors made a substantial contribution to this work. RWMV, $\mathrm{LL}$ and TA contributed to the conception and design of the review. RWMV, LL, HP-H, LA, CC-A, KC and TA screened the titles and abstracts, examined the full-text articles, extracted the data and assessed the risk of bias. RWMV, LL and TA were responsible for the analysis, interpretation of the data and the drafting of the manuscript. RWMV, LL, HP-H, LA, CC-A, KA and TA critically revised the manuscript for the important intellectual content and suggested amendments prior to submission. All authors had access to all the data in the study and can take responsibility for the integrity of the reported findings. RWMV is the guarantor.

Funding This research received no specific grant from any funding agency in the public, commercial or not-for-profit sectors.

Competing interests None declared.

Patient consent Not requried.

Provenance and peer review Not commissioned; externally peer reviewed.

Data sharing statement № additional data are available, data-extraction forms are available on request.

Open access This is an open access article distributed in accordance with the Creative Commons Attribution Non Commercial (CC BY-NC 4.0) license, which permits others to distribute, remix, adapt, build upon this work non-commercially, and license their derivative works on different terms, provided the original work is properly cited, appropriate credit is given, any changes made indicated, and the use is non-commercial. See: http://creativecommons.org/licenses/by-nc/4.0/. 


\section{REFERENCES}

1. Ilic D, Djulbegovic M, Jung JH, et al. Prostate-specific antigen-based screening for prostate cancer: a systematic review and metaanalysis. BMJ 2018;362:k3519.

2. Tikkinen KA, Dahm P, Lytvyn L, et al. Prostate cancer screening with prostate-specific antigen (PSA) test: a clinical practice guideline. BMJ 2018;362:k3581.

3. Bell N, Connor Gorber S, Shane A, et al. Recommendations on screening for prostate cancer with the prostate-specific antigen test. CMAJ 2014;186:1225-34.

4. Grossman DC, Curry SJ, Owens DK, et al. Screening for prostate cancer: US preventive services task force recommendation statement. JAMA 2018;319:1901-13.

5. Carroll PR, Parsons JK, Andriole G, et al. Prostate cancer early detection, version 1.2014. Featured updates to the NCCN Guidelines. J Natl Compr Canc Netw 2014;12:1211-9.

6. Carter HB, Albertsen PC, Barry MJ, et al. Early detection of prostate cancer: AUA Guideline. J Urol 2013;190:419-26.

7. EAU Guidelines. Edn. presented at the EAU Annual Congress Copenhagen 2018. Copenhagen.

8. Jemal A, Fedewa SA, Ma J, et al. Prostate Cancer Incidence and PSA testing patterns in relation to uspstf screening recommendations. JAMA 2015;314:2054-61.

9. Drazer MW, Huo D, Eggener SE. National prostate cancer screening rates after the 2012 US preventive services task force recommendation discouraging prostate-specific antigen-based screening. J Clin Oncol 2015;33:2416-23.

10. Nordström T, Bratt O, Örtegren J, et al. A population-based study on the association between educational length, prostatespecific antigen testing and use of prostate biopsies. Scand J Urol 2016;50:104-9.

11. Young GJ, Harrison S, Turner EL, et al. Prostate-specific antigen (PSA) testing of men in UK general practice: a 10-year longitudinal cohort study. BMJ Open 2017;7:e017729.

12. Drazer MW, Prasad SM, Huo D, et al. National trends in prostate cancer screening among older American men with limited 9-year life expectancies: evidence of an increased need for shared decision making. Cancer 2014;120:1491-8.

13. Misra-Hebert AD, Hu B, Klein EA, et al. Prostate cancer screening practices in a large, integrated health system: 2007-2014. BJU Int 2017;120:257-64.

14. Van der Meer S, Kollen BJ, Hirdes WH, et al. Impact of the European Randomized Study of Screening for Prostate Cancer (ERSPC) on prostate-specific antigen (PSA) testing by Dutch general practitioners. BJU Int 2013;112:26-31.

15. Stacey D, Taljaard M, Smylie J, et al. Implementation of a patient decision aid for men with localized prostate cancer: evaluation of patient outcomes and practice variation. Implement Sci 2016;11:87.

16. Agoritsas T, Heen AF, Brandt L, et al. Decision aids that really promote shared decision making: the pace quickens. $B M J$ 2015;350:g7624.

17. Martin RM, Donovan JL, Turner EL, et al. Effect of a Low-Intensity PSA-Based Screening Intervention on Prostate Cancer Mortality: The CAP Randomized Clinical Trial. JAMA 2018;319:883-95.

18. Siemieniuk RA, Agoritsas T, Macdonald H, et al. Introduction to BMJ Rapid Recommendations. BMJ 2016;354:i5191.

19. Selva A, Solà I, Zhang Y, et al. Development and use of a content search strategy for retrieving studies on patients' views and preferences. Health Qual Life Outcomes 2017;15:126.

20. Zhang Y, Alonso-Coello P, Guyatt GH, et al. GRADE Guidelines: 19 Assessing the certainty of evidence in the importance of outcomes or values and preferences-Risk of bias and indirectness. $J$ Clin Epidemiol 2018;4356:31036-3. S0895.

21. Violette PD, Agoritsas T, Alexander P, et al. Decision aids for localized prostate cancer treatment choice: Systematic review and metaanalysis. CA Cancer J Clin 2015;65:239-51.
22. Elwyn G, O'Connor AM, Bennett C, et al. Assessing the quality of decision support technologies using the International Patient Decision Aid Standards instrument (IPDASi). PLoS One 2009:4:e4705.

23. Guyatt GH, Oxman AD, Vist GE, et al. GRADE: an emerging consensus on rating quality of evidence and strength of recommendations. BMJ 2008;336:924-6.

24. Cantor SB, Volk RJ, Krahn MD, et al. Concordance of couples' prostate cancer screening recommendations from a decision analysis. Patient 2008;1:11-19.

25. de Bekker-Grob EW, Rose JM, Donkers B, et al. Men's preferences for prostate cancer screening: a discrete choice experiment. $\mathrm{Br} J$ Cancer 2013;108:533-41.

26. Howard K, Brenner AT, Lewis C, et al. A comparison of US and Australian men's values and preferences for PSA screening. BMC Health Serv Res 2013;13:388.

27. Howard K, Salkeld GP, Patel MI, et al. Men's preferences and tradeoffs for prostate cancer screening: a discrete choice experiment. Health Expect 2015;18:3123-35.

28. van den Bruel $A$, Jones $C$, Yang $Y$, et al. People's willingness to accept overdetection in cancer screening: population survey. BMJ 2015;350:h980

29. Pignone MP, Howard K, Brenner AT, et al. Comparing 3 techniques for eliciting patient values for decision making about prostatespecific antigen screening: a randomized controlled trial. JAMA Intern Med 2013;173:362-8.

30. Gattellari M, Ward JE. Does evidence-based information about screening for prostate cancer enhance consumer decision-making? A randomised controlled trial. J Med Screen 2003;10:27-39.

31. Petrova D, Garcia-Retamero R, Cokely ET. Understanding the harms and benefits of cancer screening: a model of factors that shape informed decision making. Med Decis Making 2015;35:847-58.

32. Sheridan SL, Felix K, Pignone MP, et al. Information needs of men regarding prostate cancer screening and the effect of a brief decision aid. Patient Educ Couns 2004;54:345-51.

33. Sheridan SL, Sutkowi-Hemstreet A, Barclay C, et al. A comparative effectiveness trial of alternate formats for presenting benefits and harms information for low-value screening services: a randomized clinical trial. JAMA Intern Med 2016;176:31-41.

34. Taylor KL, Williams RM, Davis K, et al. Decision making in prostate cancer screening using decision aids vs usual care: a randomized clinical trial. JAMA Intern Med 2013;173:1704-12.

35. Wilt TJ, Paul J, Murdoch M, et al. Educating men about prostate cancer screening. a randomized trial of a mailed pamphlet. Eff Clin Pract 2001;4:112-20.

36. Montori VM, Elwyn G, Devereaux PJ, et al. Chapter 27: Decision Making and the Patient. JAMA User's guide: Users' guides to the medical literature: a manual for evidence-based clinical practice. 3rd edn.

37. $\mathrm{Yu}$ T, Enkh-Amgalan N, Zorigt G. Methods to perform systematic reviews of patient preferences: a literature survey. BMC Med Res Methodol 2017;17:166.

38. Schünemann HJ, Oxman AD, Fretheim A. Improving the use of research evidence in guideline development: 6 . Determining which outcomes are important. Health Res Policy Syst 2006;4:18.

39. Zhang Y, Alonso Coello P, Guyatt G, et al. GRADE Guidelines: 20. Assessing the certainty of evidence in the importance of outcomes or values and preferences - Inconsistency, Imprecision, and other Domains. J Clin Epidemiol 2018;4356:31061.2.

40. Lewin S, Booth A, Glenton C, et al. Applying GRADE-CERQual to qualitative evidence synthesis findings: introduction to the series. Implement Sci 2018;13(Suppl 1):2.

41. James LJ, Wong G, Craig JC, et al. Men's perspectives of prostate cancer screening: a systematic review of qualitative studies. PLoS One 2017;12:e0188258.

42. Mansfield C, Tangka FK, Ekwueme DU, et al. stated preference for cancer screening: a systematic review of the literature, 1990-2013. Prev Chronic Dis 2016;13:E27. 